\title{
Effects of Pressure on Methyl Methacrylate Polymerization and Polymer Stereoregularity
}

\author{
Baijayantimala Mohanty, Sunanda K. PaLiT, and Mukul Biswas* \\ Department of Chemistry, Indian Institute of Technology, \\ Kharagpur 721302, India
}

(Received February 5, 1987)

\begin{abstract}
In a modest pressure range of $1-250 \mathrm{~kg} \mathrm{~cm}^{-2}$, the conversion and rate in free radical aqueous heterogeneous and homogeneous solution polymerization of methyl methacrylate increase with applied pressure to a maximum value and subsequently fall to attain a limiting value with further increase of pressure. Possible effects of pressure on kinetically important steps are discussed. The molecular weights also show similar variation with applied pressure due to enhanced chain-transfer with monomer at higher pressure. The thermal stability of the polymer is not influenced in this pressure range. ${ }^{13} \mathrm{C}$ NMR spectra analyses of the polymer obtained at three different applied pressures do not reveal any differences in the percentages of isotactic, heterotactic and syndiotactic configurations in the polymer.

KEY WORDS Modest Pressure / Free Radical Polymerization / Methyl Methacrylate / Conversion / Molecular Weight / Thermal Stability /

Stereoregularity /
\end{abstract}

Polymerization reactions under high pressure have been reported ${ }^{1}$ in a pressure range of $1-3000 \mathrm{~kg} \mathrm{~cm}^{-2}$. Recently, we observed conspicuous pressure effects ${ }^{2-4}$ in the heterogeneous aqueous polymerization and homogeneous solution polymerization of acrylonittrile (AN) and methyl methacrylate (MMA) by $\mathrm{K}_{2} \mathrm{~S}_{2} \mathrm{O}_{8}-\mathrm{Na}_{2} \mathrm{~S}_{2} \mathrm{O}_{4}$ and benzoyl peroxide, respectively, in the modest pressure range of $1-250 \mathrm{~kg} \mathrm{~cm}^{-2}$.

Prompted by these observations we became interested as to whether such a modest pressure would be able to affect the polymer structure and stereoregularity. In fact, any pressure-induced cross-links would be expected to impart to the polymer a higher extent of thermal stability if the applied pressure is not sufficient enough to degrade the polymer. Furthermore, a limited number of conflicting reports $^{5-8}$ is available on the influence of high

\footnotetext{
* To whom correspondence should be addressed.
}

pressure on polymer stereoregularity. Accordingly, we examined the thermal stability and stereoregularity of PMMA produced in the pressure range 1 to $200 \mathrm{~kg} \mathrm{~cm}^{-2}$.

Our results, highlighted in this communication, confirm that while rate and molecular weight are significantly influenced the polymer stereoregularity and thermal stability are not altered in the pressure range studied.

\section{EXPERIMENTAL}

\section{Materials}

Monomer MMA (B.D.H.) was purified by a recommended procedure. ${ }^{9}$ Potassium persulfate and sodium dithionite (both E. Merck) were used without further purification. Double-distilled water was prepared by distilling ordinary distilled water with alkaline permanganate. 
(a)

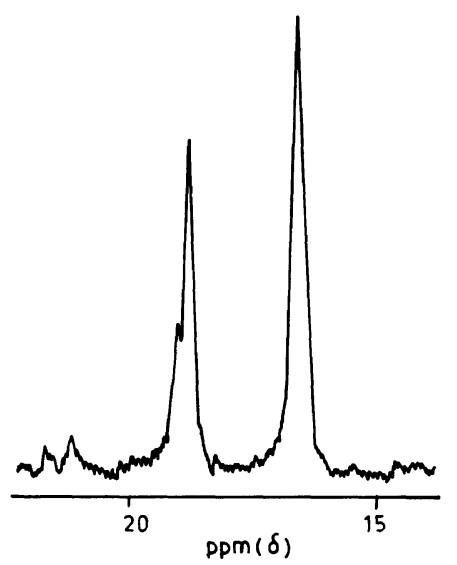

(b)

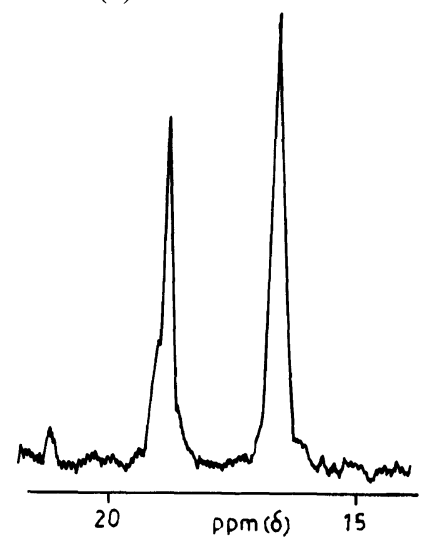

(c)

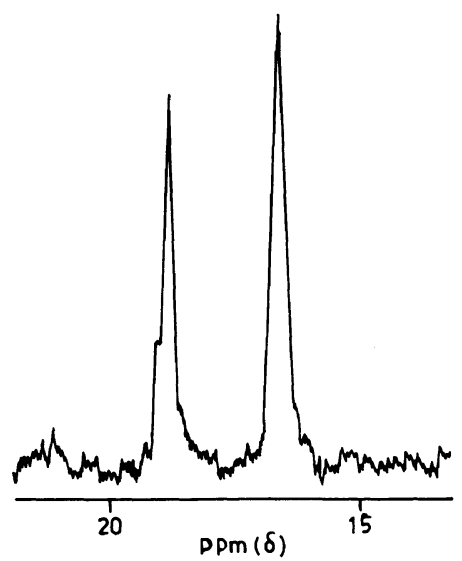

Figure 1. ${ }^{13} \mathrm{C}$ NMR Spectra of $\alpha-\mathrm{CH}_{3}$ group of PMMA prepared at (a) $1 \mathrm{~kg} \mathrm{~cm}^{-2}$; (b) $20 \mathrm{~kg} \mathrm{~cm}^{-2}$; and (c) $126 \mathrm{~kg} \mathrm{~cm}^{-2}$.

\section{Polymerization}

The polymerizations were carried out by transferring aliquots of deaerated water, MMA, initiator $\left(\mathrm{K}_{2} \mathrm{~S}_{2} \mathrm{O}_{8}\right)$ and activator $\left(\mathrm{Na}_{2} \mathrm{~S}_{2} \mathrm{O}_{4}\right)$ in a dry, cleaned pyrex glass vessel (tubular, length $=44 \mathrm{~cm}$ and diameter $=4 \mathrm{~cm}$ ), provided with B-34 standard socket. The glass vessel containing the reaction mixture was placed inside the autoclave just after the induction period as apparent from the appearance of slight turbidity in the system.

The autoclave was sealed and flushed adequately with nitrogen. The pressure inside the reaction was raised to the desired level by introducing purified and dried nitrogen gas under pressure. After a specified residence period, e.g., $2 \mathrm{~h}$, the entire liquid mixture was poured into methanol quantitatively. The precipitated polymer was isolated by filtration and dried at $60^{\circ} \mathrm{C}$. The residual polymer was ground to a fine powder and dried overnight under vacuum with the help of an infrared lamp.

\section{Thermal Analyses}

TG analyses of PMMA obtained under different pressures were performed in a Shimadzu Model DT-30 Thermal Analyzer.
The heating rate was $10^{\circ} \mathrm{Cmin}^{-1}$ and heating was continued upto $500^{\circ} \mathrm{C}$ in nitrogen atmosphere.

\section{${ }^{13}$ C NMR Spectra}

${ }^{13} \mathrm{C}$ NMR spectra of PMMA were recorded on a JEOL GX 400 FT NMR Spectrometer $\left(100 \mathrm{MHz}^{13} \mathrm{C} \mathrm{NMR}\right)$, in $\mathrm{CDCl}_{3}$ and benzene$d_{6}\left(\right.$ at $\left.70^{\circ} \mathrm{C}\right)$.

\section{RESULTS AND DISCUSSION}

\section{Dependence of Conversion and Rate on Pressure}

Table I presents some typical data on the effect of pressure on conversion, rate and molecular weights of MMA polymerization by the $\mathrm{K}_{2} \mathrm{~S}_{2} \mathrm{O}_{8}-\mathrm{Na}_{2} \mathrm{~S}_{2} \mathrm{O}_{4}$ redox pair in aqueous medium. Table II represents the corresponding data for the homogeneous polymerization of methyl methacrylate in benzoyl peroxidebenzene system. In either system, percent conversions were found ${ }^{3,4}$ to be linear upto $2 \mathrm{~h}$ of polymerization, so that a steady state is maintained and accordingly $R_{\mathrm{p}}$ was evaluated from the slope of conversion-time plots over this time. The results clearly indicate that as the pressure increases upto $20 \mathrm{~kg} \mathrm{~cm}^{-2}$, the con- 
MMA Polymerization and Stereoregularity under Pressure

Table I. Effect of pressure on the aqueous polymerization of methyl methacrylate ${ }^{a}$

\begin{tabular}{|c|c|c|c|c|}
\hline Pressure & Conversion & $R_{\mathrm{p}} \times 10^{3}$ & {$[\eta]$} & $\bar{M} \times 10^{-4}$ \\
\hline $\mathrm{kg} \mathrm{cm}^{-2}$ & $\%$ & $\mathrm{~mol} \mathrm{l}^{-1} \mathrm{~s}^{-1}$ & $\mathrm{dl} \mathrm{gm}^{-1}$ & \\
\hline 1.0 & 61.6 & 4.11 & 0.08 & 2.1 \\
\hline 10.0 & 71.0 & 4.74 & 0.13 & 6.8 \\
\hline 20.0 & 76.4 & 5.10 & 0.15 & 8.9 \\
\hline 41.0 & 69.1 & 4.64 & 0.12 & 5.5 \\
\hline 63.0 & 62.4 & 4.16 & 0.10 & 4.0 \\
\hline 85.0 & 55.6 & 3.60 & 0.09 & 3.1 \\
\hline 126.0 & 53.3 & 3.55 & 0.08 & 2.4 \\
\hline
\end{tabular}

a Polymerization conditions: $[\mathrm{MMA}]=0.48 \mathrm{M} ;\left[\mathrm{K}_{2} \mathrm{~S}_{2} \mathrm{O}_{8}\right]=2.58 \times 10^{-3} \mathrm{M}$; $\left[\mathrm{Na}_{2} \mathrm{~S}_{2} \mathrm{O}_{4}\right]=6.7 \times 10^{-4} \mathrm{M}$; temperature $=25^{\circ} \mathrm{C}$; time $=2 \mathrm{~h}$. Total reaction volume $=100 \mathrm{ml}$ (water).

Table II. Effect of pressure on methyl methacrylate polymerization ${ }^{2}$

\begin{tabular}{|c|c|c|c|}
\hline Pressure & Conversion & $R_{\mathrm{p}} \times 10^{3}$ & $\bar{M} \times 10^{-6}$ \\
\hline $\mathrm{kg} \mathrm{cm}^{-2}$ & $\%$ & $\mathrm{~mol} \mathrm{l}^{-1} \mathrm{~s}^{-1}$ & \\
\hline 1.0 & $37.2^{\mathrm{b}}$ & $2.01^{\mathrm{b}}$ & $4.2^{\mathrm{b}}$ \\
\hline 28.0 & 42.1 & 2.24 & 5.9 \\
\hline 56.0 & 46.4 & 2.47 & 6.6 \\
\hline 84.0 & 51.8 & 2.75 & 5.7 \\
\hline 112.0 & 46.5 & 2.47 & 5.0 \\
\hline 153.0 & 39.2 & 2.08 & 3.9 \\
\hline 167.0 & 37.6 & 1.99 & 3.7 \\
\hline
\end{tabular}

a Polymerization conditions: $[\mathrm{MMA}]=1.9 \mathrm{M} ;[\mathrm{BPO}]=$ $4.9 \times 10^{-2} \mathrm{M}$; solvent $=$ benzene; temperature $=50^{\circ} \mathrm{C}$; time $=1 \mathrm{~h}$.

${ }^{\mathrm{b}}$ Polymerization the same as (a) except that pressure $=$ $1 \mathrm{~kg} \mathrm{~cm}^{-2}$ (atmospheric pressure). Total reaction volume $=50 \mathrm{ml}$.

versions and hence the rates increase and thereafter decrease to a limiting value as the pressure is further enhanced from 20 to $126 \mathrm{~kg} \mathrm{~cm}^{-2}$. Likewise, in the case of homogeneous polymerization, the same features were found except that the optimum pressure at maximum conversion or rate was $84 \mathrm{~kg} \mathrm{~cm}^{-2}$ for the polymerization recipes shown in Table II. Thus, the trend observed is very conspicuous and is remarkably similar to that for the acrylonitrile systems. ${ }^{2}$

The initial increase in rate with pressure has been reported in several instances ${ }^{10}$ and may be explained conventionally in terms of an increase in propagation rate and or a decrease in the termination rate. ${ }^{10}$ Beyond the optimum pressure limit, the fall in conversion and rate with increase in pressure possibly results from decreased diffusion of monomer from the aqueous medium to the growing polymer sites, as the system becomes more dense on exposure to higher pressure. ${ }^{11}$ In fact, Sasuga et al. ${ }^{12,13}$ has confirmed from $(P-V)$ relationship studies with methacrylic, acrylic ester and acrylonitrile that monomer molecules are indeed under short-range alignment in the pressure range in the liquid phase. Such alignments will evidently create a situation unfavourable to diffusion of the aligned monomer molecules to the propagation sites to a greater extent than when they are randomly distributed in solution normally in the absence of any pressure. Accordingly, a fall in conversion and rate would be expected.

In any case, the actual situation is probably more complex since chain termination is also reduced in this "aligned matrix." However, the observed fall in the overall rate endorses that the decrease in the propagation rate due to decreased diffusion kinetically outweighs the chance of increase in rate due to decrease in termination. ${ }^{12}$

It is well known that marked gel effect 
Table III. Thermal stability of poly(methyl methacrylate) ${ }^{a}$

\begin{tabular}{|c|c|c|c|c|}
\hline \multirow{3}{*}{$\frac{\text { Weight loss }}{\%}$} & \multirow{2}{*}{\multicolumn{4}{|c|}{$\frac{\text { Temperature }}{{ }^{\circ} \mathrm{C}}$}} \\
\hline & & & & \\
\hline & $\begin{array}{l}\text { PMMA } \\
\text { (1 atm) }\end{array}$ & DTA & $\begin{array}{c}\text { PMMA } \\
\left(126 \mathrm{~kg} / \mathrm{cm}^{-2}\right)\end{array}$ & DTA \\
\hline 10 & 350 & \multirow{8}{*}{$390^{\circ} \mathrm{C}$ (endothermic peak) } & 360 & \\
\hline 20 & 365 & & 370 & \\
\hline 30 & 375 & & 380 & $440^{\circ} \mathrm{C}$ (endothermic peak) \\
\hline 40 & 380 & & 390 & \\
\hline 50 & 390 & & 400 & \\
\hline 60 & 400 & & 410 & \\
\hline 70 & 410 & & 420 & \\
\hline 80 & 430 & & 435 & \\
\hline
\end{tabular}

a Polymerization conditions: $[\mathrm{MMA}]=0.48 \mathrm{M} ;\left[\mathrm{K}_{2} \mathrm{~S}_{2} \mathrm{O}_{8}\right]=2.56 \times 10^{-3} \mathrm{~m} ;\left[\mathrm{Na}_{2} \mathrm{~S}_{2} \mathrm{O}_{4}\right]=6.7 \times 10^{-4} \mathrm{M}$; temperature $=25^{\circ} \mathrm{C}$; time $=2 \mathrm{~h}$. Calculated from TG curves for PMMA.

influences the polymerization of MMA and that pressure effect tends to enhance such gelation. However, attempts to explain the presently observed trend on the basis of the recent knowledge on gel effect ${ }^{13}$ would be probably not meaningful. This is because, under the modest pressure range used in this case, the conversion time curves do not reveal any autoacceleration ${ }^{3,4}$ and neither are the viscosity values drastically increased, ${ }^{3,4}$ which rule out any extensive gelation.

\section{Molecular Weight Trends}

The molecular weights of the polymer tend to rise initially with an increase in pressure and fall thereafter to a limiting value. This implies that bimolecular transfer reactions ${ }^{11}$ of the polymer radicals with monomer molecules assume dominance in the increasing pressure range. However, the possibility of an exclusive chain transfer in this system is overruled since the conversions are also affected considerably thus, endorsing that termination is also important in this sytem. In fact, we have evaluated the chain transfer to monomer values both in homogeneous ${ }^{4}$ as well as heterogeneous ${ }^{3}$ polymerizations of MMA under normal and high pressure which clearly support our con- tention.

\section{Thermal Stability Characteristics}

Table III compares the thermal stability of PMMA prepared at two different pressures, i.e., $1 \mathrm{~kg} \mathrm{~cm}^{-2}$ and $126 \mathrm{~kg} \mathrm{~cm}^{-2}$. Apparently PMMA is initially stable upto $350^{\circ} \mathrm{C}$; thereafter, DTA reveals an endothermic peak at $390^{\circ} \mathrm{C}$ (PMMA prepared at atmospheric pressure) and at $440^{\circ} \mathrm{C}$ (PMMA prepared at $126 \mathrm{~kg} \mathrm{~cm}^{-2}$ ) due to chain depolymerization reactions. ${ }^{14}$ However, PMMA obtained in either system undergoes $80 \%$ weight loss at $430-435^{\circ} \mathrm{C}$. Table III further reveals that PMMA prepared under high pressure exhibits a tendency to a slightly higher stability but, keeping in view the uncertainty of experimental measurements, $1-3 \%$ variation in stability should perhaps be regarded with caution.

The thermal stability of PMMA is reportedly affected much by the existence of chain end double bonds (weak links). ${ }^{15}$ Any possibility of an enhanced gel effect with increasing proportion of unimolecular termination and chain transfer should diminish the concentration of chain end double bonds and enhance stability. However, as argued earlier, extensive gelation possibly is not induced in the pressure 
MMA Polymerization and Stereoregularity under Pressure

Table IV. Chemical shift (ppm) of poly(methyl methacrylate) prepared under different conditions ${ }^{\mathrm{a}}$

\begin{tabular}{|c|c|c|c|c|c|}
\hline \multirow{2}{*}{$\begin{array}{c}\text { Atmospheric } \\
\text { pressure }\end{array}$} & \multirow{2}{*}{$\begin{array}{c}\text { Pressure } \\
\left(20 \mathrm{~kg} \mathrm{~cm}^{-2}\right)\end{array}$} & \multirow{2}{*}{$\begin{array}{c}\text { Pressure } \\
\left(126 \mathrm{~kg} \mathrm{~cm}^{-2}\right)\end{array}$} & \multicolumn{3}{|c|}{ Literature $^{b}$} \\
\hline & & & Value & Ass & nment \\
\hline 16.7 & 16.6 & 16.6 & 16.7 & $r r$ & \\
\hline 18.8 & 18.8 & 18.8 & 19.9 & $m r$ & $\alpha-\mathrm{CH}_{3}$ \\
\hline 19.1 & 19.0 & 19.0 & 23.5 & $m m$ & \\
\hline 44.6 & 44.6 & 44.6 & 45.6 & $r r$ & $=C^{\prime}$ \\
\hline 45.0 & 45.0 & 45.0 & 46.0 & $m m$ & \\
\hline 51.8 & 51.8 & 51.7 & 51.0 & & $-\mathrm{OCH}_{3}$ \\
\hline 54.2 & 54.3 & 54.3 & 52.0 & $m m$ & $=\mathrm{CH}_{2}$ \\
\hline 54.5 & 54.5 & 54.5 & 55.0 & $r r$ & \\
\hline 177.1 & 177.1 & 177.1 & $177.2^{\mathrm{c}}$ & $\mathrm{C}$ & \\
\hline 178.0 & 178.0 & 178.0 & 178.0 & & 冫C $=\mathrm{O}$ \\
\hline 178.4 & 178.5 & 178.5 & $179.0^{c}$ & $\mathrm{C}$ & \\
\hline
\end{tabular}

${ }^{a}$ Polymerization conditions: $[\mathrm{MMA}]=0.48 \mathrm{M} ;\left[\mathrm{K}_{2} \mathrm{~S}_{2} \mathrm{O}_{8}\right]=2.5 \times 10^{-3} \mathrm{M} ;\left[\mathrm{Na}_{2} \mathrm{~S}_{2} \mathrm{O}_{4}\right]=0.67 \times 10^{-3} \mathrm{M}$; temperature $=25^{\circ} \mathrm{C}$; time $=2 \mathrm{~h}$. Total reaction volume $=100 \mathrm{ml}$ (water).

b Literature data were obtained from ref. 16 and 17.

c The carbonyl region is reported to provide information on the pentad structure. ${ }^{16,17)}$

Table V. Effect on pressure on the stereochemistry of methyl methacrylate polymerization

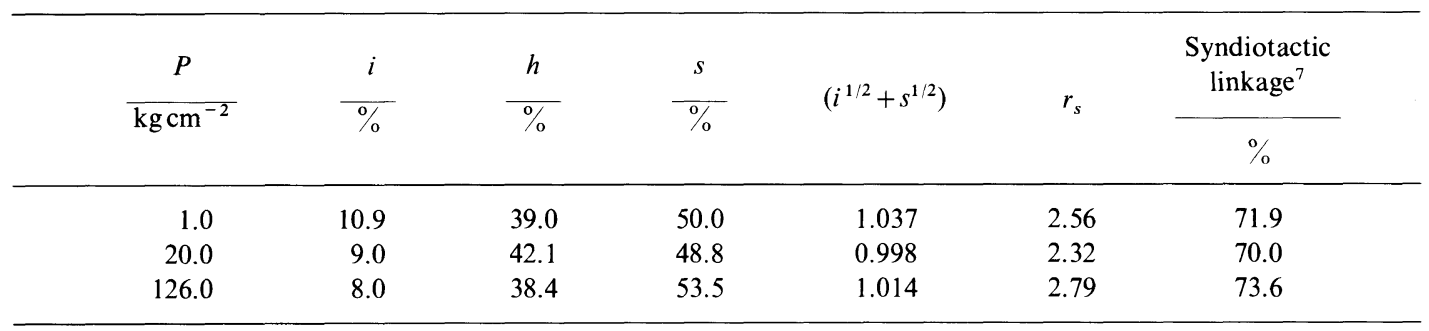

range used in this sytem, so that the thermal stability of the polymer is not conspicuously enhanced.

Effect of Pressure on PMMA Stereoregularity Table IV presents the observed ${ }^{13} \mathrm{C}$ NMR peak characteristics of $\alpha-\mathrm{CH}_{3}$, > $\mathrm{C}_{-}^{-},-\mathrm{OCH}_{3}$, $=\mathrm{CH}_{2},>\mathrm{C}=\mathrm{O}$ in PMMA. Figure 1 gives the $\alpha$ $\mathrm{CH}_{3}{ }^{13} \mathrm{C}$ NMR spectra at three different pressure ranges indicated. Lyerla ${ }^{16}$ and Peat ${ }^{17}$ have carried out structure-tacticity assignments of radically polymerized PMMA which are also shown in Table IV for comparison. ${ }^{18}$

Quantitative estimation of polymer tacticity has been made from the areas of isotactic $(i)$, syndiotactic $(s)$, and heterotactic $(h)$ peaks $^{6-8}$ due to $\alpha-\mathrm{CH}_{3}$ groups and relevant data are presented in Table V. Apparently, within the range $1-126 \mathrm{~kg} \mathrm{~cm}^{-2}$, polymer tacticity is not altered. Notably, Walling and Tanner ${ }^{7}$ reported that in the pressure range 1$8000 \mathrm{~kg} \mathrm{~cm}^{-2}$, the amount of isotactic link increased three-fold $(4-12 \%)$ while syndiotactic configuration decreased. However, at a given pressure, various configurations follow the order: isotactic $<$ heterotactic $<$ syndiotactic which is in line with observation of Walling and Tanner $\left(1-8000 \mathrm{~kg} \mathrm{~cm}^{-2}\right.$ pressure range).

Treatment of the stereo-addition of successive monomers units as a classical copolymerization problem would also permit evaluation ${ }^{7}$ of ' $r$ ' and ' $r$ ' (reactivity ratios fo 
syndiotactic and isotactic addition) and assuming "ideal" behavior $\left(r_{\mathrm{s}}=1 / r_{\mathrm{i}}\right)$ the condition $i^{1 / 2}+s^{1 / 2}=1$ would be expected to be valid. ${ }^{7}$ The results of Table $\mathrm{V}$ support these expectations in the present system and confirm that in the pressure range, the percentage syntiotactic linkage ${ }^{7} 100 r_{\mathrm{s}} /\left(1+r_{\mathrm{s}}\right)$ is not significantly altered.

The absence of any pressure effect on the tacticity, despite the proposed short range alignment of liquid monomer molecules under pressure, implies that the extent of such alignments is not enough to induce stereoselective monomer addition.

Acknowledgements. The authors thank Professor T. Uryu, Institute of Industrial Science, University of Tokyo, Japan, for the measurement of ${ }^{13} \mathrm{C}$ NMR spectra, and the authorities of I.I.T., Kharagpur for the use of their facilities.

\section{REFERENCES}

1. Y. Ogo, J. Macromol. Sci., Rev. Macromol. Chem. Phys., C24, 1 (1984).

2. B. Mohanty, S. K. Palit, and M. Biswas, J. Appl. Polym. Sci., 32, 2969 (1986).

3. B. Mohanty, S. K. Palit, and M. Biswas, J. Polym.
Sci., Chem. Ed., submitted (1986).

4. B. Mohanty, S. K. Palit, and M. Biswas, J. Polym. Sci., Lett. Ed., 25, 187 (1987).

5. G. A. Trementozzl and R. Buchdahl, J. Polym. Sci., 12, 149 (1954).

6. J. A. Bovey and G. V. D. Tiers, J. Polym. Sci., 44, 173 (1960).

7. C. Walling and D. D. Tanner, J. Polym. Sci. A, 1, 2271 (1963)

8. B. D. Coleman, J. Polym. Sci., 31, 159 (1958).

9. S. R. Palit and T. Guha, J. Polym. Sci., 34, 243 (1959).

10. F. M. Merrett and G. R. Norrish, Proc. R. Soc. London, Ser. A, 206, 309 (1951).

11. K. E. Weale, "Chemical Reactions at High Pressure," E and F. N. Spon, Ltd., London, 1967.

12. T. Sasuga and M. Takehisa, J. Macromol. Sci. Chem., A12, 1343 (1978); T. Sasuga, S. Kawanishi, and M. Takehisa, J. Macromol. Sci., Chem., A14, 605 (1980).

13. I. Mita and S. Horie, J. Macromol. Sci., Rev. Macromol. Chem. Phys., C27, 91 (1987); T. J. Tulig and M. V. Tirrell, Macromolecules, 14, 1501 (1985).

14. W. F. Billmeyer, "Textbook of Polymer Science," John Wiley and Sons, Inc., New York, London, Sydney, Toronto Toppan Company Ltd., Tokyo, Japan, 1971.

15. I. Mita, "Aspects of Degradation and Stabilization of Polymers," Jellinek, Ed., Elsevier, Amsterdam, 1978.

16. J. R. Lyerla, T. T. Horikawa, and D. E. Johnson, J. Am. Chem. Soc., 99, 2463 (1977).

17. I. R. Peat and W. F. Keynolds, Tetrahedron Lett., 1359 (1972).

18. H. T. Edzes and W. S. Veeman, Polym. Bull., 5, 255 (1981). 